\title{
PRACTICAL ASPECTS OF THE STRATEGY IMPLEMENTATION FOR REGIONAL AND LOCAL INNOVATION SYSTEMS DEVELOPMENT
}

\author{
Dr Victoriia Nikolayevna Ryapukhina* \\ Belgorod State Technological University named after V.G. Shukhov, Russia \\ Dr Sergey Nikolaevich Glagolev \\ Belgorod State Technological University named after V.G. Shukhov, Russia \\ Emiliya Viktorovna Suprun \\ Belgorod State Technological University named after V.G. Shukhov, Russia \\ Dr Peter Pavlovich Taburchak \\ Saint Petersburg State Technological Institute, Russia
}

Many authors have turned their research interests to the problem of innovative development as a result of global trends that have led to the transition to an innovative functioning of an economy. This research focuses on territorial innovation systems represented by the regions and municipalities. The major aim of the study has several objectives associated with the theoretical analysis of practical aspects of the problem in regional and municipal levels. First of all, there is a need to provide a critical review of the literature devoted to innovative development of regional systems. Secondly, the role of territorial authorities in an innovation process is needed to be examined. Finally, this study has an overarching objective to identify the opportunities and evaluation mechanisms for innovation potential of regions and municipalities, as well as to formulate a complex of measures for its development. Basis of this work amounted to actual works of Russian and foreign scientists, the analysis of the Russian experience of innovation, as well as the recommendations of foreign experts. The research is based on Russian and international academic literature, innovation-related articles, the analysis of Russian innovative experience as well as the foreign experts' recommendations related to the issue.

Key words: Innovation, Innovation system, Innovative development, District, Municipality, Cluster, Special economic zone

\section{INTRODUCTION}

It is obvious that the world economy is experiencing a qualitatively new development stage. Hence, there is a need to pay attention to some features of the transition to the modern economy: innovation are becoming demanded by not only individual companies but a national economy. Moreover, a new economic category which is human capital has been formed in order to accumulate funds and make profit. Innovation ensures efficient use of not only labor but also capital. As a result, a government needs to adjust the direction of the innovation market as well as take responsibility and expenses for maintaining ongoing growth through innovation. This determines the feasibility of development and implementation of a coherent national innovation policy.
According to Mukhamedyarov, innovation policy is a complex of measures aimed at innovation enhancement, improvement its efficiency and increased use of the results in order to accelerate a national socio-economic development and completely satisfy the social needs [10]. Public innovation policy finds its practical expression in the specifically formulated long-term implementation strategy and tactics that consist of practical aspects of creating a favourable innovation environment.

Innovative environment becomes a system when the relevant features and structural elements are available. The relationships between them enabling to analysis an innovative environment as a system are also important. Kirillina and Myasoedov point out that the type of global economy has been changed as a result of the transition on a 
path of development of national innovation systems [05]. Zarkovic has mentioned that methodological approaches to territorial innovative development in the context of modern theories of economic development have been reflected in the concept of innovation systems [19]. The original theory of innovation systems by Christopher Freeman only explained the national differences in the level of technological development. Nevertheless, the relationship between elements of innovation systems has leaded in this field lately. Doroshenko Y.A. believes that a relationship between the nature of innovation and forms of its development determines the principal place of the content while the forms determine a side which is modified depending on the specific conditions of its existence. Form of development being relatively independent has an opposite active effect on the nature of innovation. Particularly, a form corresponding to the content accelerates innovative development, while the form no longer corresponding to the changed content hinders its further development [02].

In connection with the above, the relevance of examining the problem of implementation of innovative development in the context of innovation systems functioning becomes obvious. The aim of this paper is a theoretical analysis of the practical aspects of the issue at regional and municipal levels. In particular, the objectives of this research were the following:

- To create a theoretical framework of innovative development of the territorial systems based on the analysis and generalization of researches of leading Russian scientists;

- To examine the role of territorial authorities in innovative development, taking into account the practical experience of Russian reality as well as the recommendations of foreign experts.

The practical significance refers to the usefulness of the findings from our study. As research results the authors have identified the opportunities and evaluation mechanisms for innovation potential of regions and municipalities as well as formulated a complex of measures for its development based on the results of the evaluation of innovative potential of territorial association, its place and role in the national economic system.

\section{THEORETICAL FRAMEWORK OF FORMATION OF REGIONAL INNOVATION SYSTEMS}

There is a belief that studying of national innovation systems (NIS) is a relatively new global research sector. Some researchers devote their researches to the development of the theoretical foundations of the NIS (NIS theory), while others prefer to create the concept of NIS (conceptual approach) [09]. For the first time the term "NIS" was used by Christopher Freeman in 1987 in his study devoted to the technological policy in Japan. However, Bengt-Ake Lundvall who published the book "The national system of innovation" in 1992 was "the man who invented the NIS". According to the Swedish scientist, professor Lundvall, in a narrow sense innovative system includes companies and system of their interactions, as well as the interaction of these companies with universities and research institutes. In a broad sense innovative system includes an education system, the funding sources and the public interventions, including legal regulation and social security [08].

Researchers identify 3 main approaches to understanding a national innovation system:

1. According to Freeman, NIS is considered as a set of institutions aimed at the generation and diffusion of innovation (practical, commercial approach);

2. According to Lundvall, NIS is considered as a set of interrelated economic mechanisms and activities that provide innovative process (functional approach);

3. According to Abramowitz, NIS is considered as a part of a national economic system. It provides an organic integration of innovative processes into the progressive development of an economy and society [09].

Russian scientists basically follow the first two approaches, which is reflected in the various studies as well as the regulatory and program documentation. Malashevskaya and Stryabkova point out that nowadays national innovation system as an economic category is more often represented as a combination product of globalization and differentiation in innovation sphere [09]. From their point of view, according to the development trend of world globalization process, recent scientific and technical researches are becoming international and there is a blur- 
ies between local innovation systems. Hence, it determines the future revision of approaches to understanding the NIS as a "public". Modern authors identify different hierarchy levels of innovation systems, depending on the geographical coverage and the nature of relationship between the participants in an innovation process. The hierarchy levels are the following: global, national, regional and municipal. For several reasons, the concept of global innovation systems and innovation systems in municipalities has not been completely formed yet.

Some authors believe that present processes of regional integration led to the development of transnational and international innovation systems due to the political, economic and other reasons. It is worth saying that there are a certain amount of countries involved in an active scientific and technical cooperation. As a result, it was concluded that transnational innovation systems (TNIS) (as characteristics of "pre-global") exist due to the fragmentation and heterogeneity of the global innovation system [19]. Also Zarkovic points out that an innovation system passes transitional stages during the development process due to the fact that an economic system is transformed from one type to another [19]. According to the modern concept of innovation systems, there are the following reasons of selection of transitional systems:

1. Regularity of transitive period in the system development for qualitative transition to a higher level;

2. A need to examine the present state of innovation systems, which are mostly in the borderline or intermediate stages of development;

3. The validity of examining the trans-territorial innovation systems to identify deficiencies and heterogeneity of their structure.

Many authors agree that the principle of innovative development does not depend on the type of the state, nor of the political regime. Indeed, according to the international scientists, overall efficiency of the NIS is about the same either in the federal Germany and unitary France as well as communist China. However, NIS structure may be substantially different in different countries depending on the major goals and objectives. For instance, French NIS's objective is an increase on additional workplaces while German one is development of advanced technologies.
Russian scientists are convinced that the main aim of national innovation systems is to ensure sustainable economic development and improved quality of life through the creation of additional workplaces, both in science and manufacturing and service sector. The second way is to increase production of high-tech products and rise the household incomes in order to increase revenue budgets [09]. Nevertheless, the major elements of NIS remain constant and key elements are usually the following: the legislation and regulation on innovation, the entities of innovation and innovation infrastructure. According to Malashevskaya and Stryabkova, the main participants in an innovation process are government, innovation adopters, innovation-active companies and research organisations. These researchers suggest that structural components of NIS such as organisations of private and public sector interact with each other in the framework of legal and informal norms of behaviour. A synthesis of public regulation and market mechanisms is a fundamental principle of building the innovation system. The main obstacle is the definition and delimitation of influence spheres and functions of public and private sectors [09].

\section{THE ROLE OF REGIONS AND MUNICIPALITIES IN INNOVATIVE DEVELOPMENT}

Nowadays regional authorities can no longer perform only executive function under conditions of modern capitalism and government decentralisation. However, according to Kanishchev and Usmanov, even though the relationship between national and regional authorities have been qualitatively rebuilt, have received substantial theoretical and methodological support and sufficient funds, the level of interaction with their regional municipalities is still not sufficient, considering the serious problems [03]. Foreign experience shows that progressive municipalities can make a significant contribution to innovative development of regions. In an interview Lundvall said there were global positive trends of innovation policy. It's expansion has been outlined, including organizational, institutional and demand factors. However, the use of targeted economic development models (e.g. based on production function) and the limited indicators of innovation development (e.g. an increase on total product) were highlighted as barriers to the development of this trend [08]. Chitaya believes that different indicators may indicate the relatedness of NIS 
regional and macro-regional innovation models. These indicators include innovation activity, intensity of organizational and economic ties in the context of industrial development and market introduction of product, process and organisational innovation, speed and depth distribution of innovative processes etc. [01].

Authorities of municipalities may be delegated to $70 \%$ of current operational tasks, that would allow the regional authorities to focus on strategic issues. Sometimes only the interests of business entities making an active contribution into the innovative development are sufficient for design and implementation of innovation policy. This approach significantly increases the imbalance of innovation system and led to greater increase of laggard areas with low levels of innovative development. It also hinders implementation mechanism of complex building of innovative infrastructure and creating an innovative environment. Lundvall says the difference in levels of development between regions has become the cause of the financial difficulties in the EU because common currency and common market are not satisfied the conditions for economic growth [08]. It is very important to consider the principle of limited resources and justify the advisability of investing and making efforts to innovative development of individual entities based on the evaluation of innovative potential, development and activity. However, authorities often forget that "even the most passive in terms of innovation municipalities actually able to make a significant contribution to the rise of innovative regional education, including the use of indirect methods of exposure" [03].

Kanishchev and Usmanov point out that no municipalities are passive in a regional innovation sector. They make contribution to development of an innovative scenario to one degree or another. The problem is that methodology for assessing innovation potential, the level of innovative development and innovation activity related to municipalities has not been developed yet. Such methodology would allow to obtain information, make a comparison with other municipal entities grouped according to the certain criteria. Moreover, it would highlight the strengths and weaknesses as well as develop a program for their further development, depending on the nature of their functioning, resource potential and their place and role in the NIS. These authors classify six basic roles of municipalities, depend- ing on their position in the RIS, the nature of their relationships and role of their participation in innovative development of a region [03]:

- intelligent donors;

- investors;

- generators of innovation;

- integrators;

- manufacturers;

- consumers (popularisers).

Each of these roles characterise some institutional factors presented by socio-economic indicators. Generators are characterized by scientific and technical (a number of scientific and technical entities in a municipality), intellectual (scientific and technical personnel and their achievements) and logistical factors (infrastructure for scientific and technical activities). Integrators represent factors of innovation infrastructure, credit and financial institutions (multiplicity of sources) and institutes for economic coordination and distribution of risks (insurers and investment funds, venture capital agencies). Manufacturers represent factor of placement of productive forces (rational tendencies of the most efficient allocation of production) and factor of entrepreneurial capital and production infrastructure. Investors are characterized by factor tax capacity, system of innovation funds and factor of investment activity of local business organisations. Consumers provide factor of innovative demand formation and factor of formation of brand innovation.

Returning to the issue of innovation transitional system, we must add that reproductive capital of a region is an open system. Russian scientist Vostretsov has analysed the variability of indicators characterising the inter-regional mobility of innovative capacity and the level of risk of transboundary movements of reproductive potential. Moreover, the researcher suggests using the average value of import and export capabilities to assess a risk level. The higher the volatility of import-export ratio the higher the risk. According to Vostretsov, the relationship between regional risk and reproductive potential occurs because of fluctuations of changing inter-regional elements that may lead to insufficient reproduction of necessary resources and factors in a region as well as excess capacity of one element of reproductive potential and weak capacity of another. Consequently, it would negatively affect the value of total reproductive potential and lead to its structural 
"dissynchronization" and, eventually have a negative impact on the reproduction of regional product [17]. The author also recommends to maintain a stable import and export of innovative potential on the same level. Import should tend to a maximum while export - to a minimum. This process focuses on building of capacity and achieving the long-term qualitative economic growth.

\section{EVALUATION OF INNOVATION POTENTIAL OF REGIONS AND MUNICIPALITIES. MEASURES FOR THEIR DEVELOPMENT}

Territorial development planning has been widespread in foreign and domestic practice. Spitsin believes that the development strategy (focused on the long-term period 10 to 25 years) of a region program (short and medium term is usually 2 to 5 years) has been formed based on analysis of a current level of regional development, its strengths and weaknesses. Hence, it is necessary to carry out an annual monitoring process of socio-economic development of a territory in order to ensure the implementation of strategies and programs [13]. It is important to determine a threshold of competitiveness, potential and growth rate of competitiveness of regions and municipalities in order to evaluate the innovative potential. According to Stryabkova and Kurbatov, regional competitiveness is its ability to produce goods and services that meet the requirements of domestic and global markets; to create conditions for enhanced regional resources in order to ensure the growth of potential of region clustering and competitiveness of business entities. The major purpose is to ensure regional quality of life at the level of world standards [14]. We can highlight the following aspects of competitiveness of a region or municipality that need reasonable measures for the development of innovative potential:

1. Innovation, investment and intellectual resources;

2. Clustering;

3. The gross regional product (GRP).

Lundvall points out that a government has historically played a major role in implementation of technological breakthroughs. There is a great need to develop a unified model of public management of regional innovation potential. It is reasonable to use elements of the Soviet innovation software infrastructure (the Rationalization
Invention Bureau (RIB), the All-Union Society of Inventors and Innovators (VOIR), Scientific and Technical Union (STU), etc.) as a basis of the model. There are a lot of regional elements of innovation infrastructure such as business incubators, packaging companies, innovation and technology centers, industrial and techno parks have been currently established. However, they are inferior to the Soviet counterparts because of their purely pragmatic and commercial orientation, fragmentation and lack of a unified approach to the implementation of innovation process. It is necessary to have a clear idea in what form, where, and how to conduct organizational, technological and economic impact on the integration of innovative capabilities of enterprises and public authorities in relation to specific regional conditions. Yudin and Gusev believe that the current practice of determination of scientific and technical priorities aim at maintaining the existing institutional structures [18]. Solving this problem would eliminate the imbalance in development and use of innovation as well as provide restructuring of regional economy needed for the transition to an innovative development.

Lundvall has called "institutions" as a drawback of Russia's territorial innovation systems. By "institutions" he means a system of rules, regulations and relationships in an economy. The scientist believes that there is a lack of confidence in Russia. Moreover, economic offenses undermine development of an entire innovation system. Russia must create a new kind of collective solidarity to fight against corruption and crime to overcome these difficulties. What is more, there is a need to change the incentive system in order to encourage the creative approach among not only wage workers but also entrepreneurs [08]. Indeed, Vaganova says that the qualitative level of development of innovation infrastructure determines the duration of innovation implementation; forms the prioritised portfolio of innovations; promotes trade, fiscal and social efficiency of innovative production [16]. She highlights the following main characteristics of innovation infrastructure ensuring its effectiveness and functionality [16].:

- high scientific and technical potential;

- sufficient level of integration with financial sources;

- development of information component (allows to accumulate innovative experience); 
- flexibility and adaptability;

- universality (the ability to equally and effectively implement innovation in different sectors of an economy);

- decentralisation (the ability to solve regional problems of full innovation cycle);

- professionalism of entities of innovative activity;

- infrastructure staffing;

- application of principles of economic and social approach.

It is worth saying that a system for personnel training is considered to be the main basic element of the creating such infrastructure.

Modern science and technology policy is characterised by insufficient level and low rate of diffusion. Soviet science had been characterised by large scale, full state funding and centralised management. Present amount of investment in innovation is not able to provide a full-scale technological breakthrough for several reasons. However, Lundvall says that it is wrong to focus only on R\&D. [08]. Yudin and Gusev point out that adoption of $R \& D$ reflects the interest of enterprises in innovation and stimulates a diffusion of contacts with outside companies. At the same time research organizations are important sources of information for updating competitive strategy by carrying out the processing of scientific and technical information [18]. Maintenance or improvement the pseudo innovation not require long-term preparation and solid technological changes. However, they will no longer give any economic effect within a couple of years.

Commenting the current state of the national innovation system, Lundvall also said that it is necessary to pay more attention to modernisation of an education system and a labor market, as well as the organisation of labour by reforming a labour market (e.g. flexible system of social guarantees) and an education system (e.g. ensuring equal access to education) in order to develop NIS. Also Lundvall considers the experience of creating NIS in Finland (pragmatic approach) and Norway (cooperation between trade unions and employers' organisations) as positive. It is negative in Sweden and UK taking into account the negative attitude of the private sector to the public, poor regime of labour relations and excessive focus on transformation of a research into innovation [08].
Creating clusters is one of the most effective measures for innovative development of a region and municipalities. It is necessary to identify the absolute and comparative advantages of a territory where production is localised at the initial stage of cluster formation in order to subsequent assessment of its effectiveness. The synergistic effect occurs in the form of additional revenue and cost reduction. According to Lobanova and Ismagilova, a quantitative effect is also a result of qualitative changes. While a quantitative effect can be calculated, no quantitative effect can be only identified using quantitative changes. The efficiency determines the presence of unconditional prerequisites to the formation of business units [07]. The effect can be estimated by comparing results before and after the merger. It is important to consider that a number of new costs occur during and after the merger. The unit cost of a product or service is usually smaller inside cluster than outside it, there is also a reduction of costs on business processes. Clustering allows to use new and unused capacity that leads to an increase in production volume. It is necessary to compare the additional income and additional costs in order to understand whether the cooperation worth it. Factors of cost savings are different because forms of integration are also different. These factors are the following: scale effect; complementarity and combining; changeable financial capacity; vertical and horizontal integration (reduction of transaction costs); improvement of quality and efficiency of management. Shevtsova and Troshin consider a large enterprise or scientific school determining economic or other innovative strategy of the entire system as a basis of the cluster mechanism [15]. The mechanism of public-private partnership is also considered by many researchers as an effective way to foster regional innovation and increase regional competitiveness while creating technology-innovative special economic zones. It is possible due to the growth of individual potentials and synergistic effect.

\section{CONCLUSION}

Development of effective regional innovation systems is one of the most important aspects of the modernisation of Russia that will improve the quality of life and increase the competitiveness of the economy. National innovation system is a set of a public innovative policy, all kinds of innovation and its main resources. 
The main objective of this system is saturation of all spheres and sectors of an economy with innovation processes. Innovative development should be economically sustainable, that is a guarantee of positive progressive dynamics. An increase in prestige of entrepreneurs as initiative people is an important factor in the development of NIS. They develop new business based on innovative ideas that commercialise innovations. According to Pokhilko, a formation of competitive business is primarily directed to implementation of the most effective investments in human resources generating new ideas and promoting the development of small business. This development can not be completed without regional intervention of local authorities. [12].

The major functions of public regulation of development of innovative systems are the following: assistance in the improvement strategy of innovative development; identification of weaknesses in the organisation of innovation processes and their removal; collection and analysis of information to make decisions about support for specific innovative projects and programs. There are three types of models of innovation development in the world practice. The traditional or linear model is a complete innovation process presented in the developed countries of the EU and the USA. It is characterised by a high level of fundamental and applied science which is primarily funded by not private investors but a government. The adoption model is presented in Japan, South Korea and China, where fundamental and applied science is missing or underdeveloped. This model is focused on high-tech import. High-tech products are usually exported to countries where the technology was acquired. The model of multiple sources of innovation or alternative model suggests the possibility of innovation in any link of innovation system. It is focused on not only technological and product innovation, but also on innovation in institutional, organizational and administrative sphere. These systems are characterised by import and distribution of technology, focused on personnel training, development of services, financial, banking and insurance sectors as well as tourism and agriculture. The fundamental and applied science is not available in such a model. Many researchers, Karlinskaya in particular, believe that it is advisable to apply the two models of management in Russia: the functional one ant the model of multiple innovation [04].
In the studies of foreign and Russian scientists the innovation process is presented by several stages that can be generally characterised as a research stage, stage of development activities, industry adoption and implementation of innovative products. In opinion of Nikulina, an innovation process can be completely or incompletely represented in different regions, depending on funding, personnel policy and other factors. This author suggests that an entire innovation process is an innovation cycle divided into 4 groups: information and knowledge, innovation, production and consumption [11]. In this regard, the researcher recommends to use the factor model to prioritise the development of RIS or select the prevailing model of innovative development of a region. This model shows that, for example, a compelling level of science development, technology, infrastructure and human resources is needed to implement the first stage of an innovation cycle. In case there are developed scientific, technical, infrastructure, personnel and environmental components in a region, it is possible to implement the second stage of the innovation cycle. Technological, industrial and human resources components are needed for implementation of the third stage of the innovation cycle. Infrastructure and environmental components are needed to implement the final stage of the innovation process which is a consumption. Such a systematic analysis provides a reasonable idea of the possibilities and limitations of innovative development of a region and allows to select the management tools for regional innovation.

\section{SUMMARY}

Considering the global trends determined the advisability of transition of all levels economic entities to innovative type of development, the actual problem can be considered the formation and implementation of appropriate strategies. In this regard, the need for a steady regional development within the national socio-economic systems focuses on regional and local innovation systems. The evaluation of innovative potential is one of the practical aspects of implementation of the development strategy for subjects of innovative activity in order to determine their place and role in a national innovation system as well as to develop a set of measures to accelerate and improve the development efficiency. The authors believe that the following unified comparative and quantitative indicators can be applied to 
assess the innovative capacity: competitiveness index; human development index; networked readiness index; territorial innovation index; territorial investment attractiveness index; index of conditions of development (real estate and infrastructure, human resources, financial resources, administrative climate and security, suppliers).

Thus, measures to operationalize the strategy of innovative development must be balanced with the potential and conditions of a particular territorial system. These measures should be primarily aimed at overcoming negative factors in an innovation process of each specific region, depending on its place and the role in this process. To summarise, the following main barriers to implementation of the development strategy of territorial innovation systems can be identified: undeveloped public institutions; limited competition; declining quality of education; underdeveloped financial markets; low competitiveness of companies.

There are many well-known measures of implementation of the development strategy of innovation systems such as effective public regulation of innovation market, innovation infrastructure, investments in science and education. However, according to the national and international experience, it is advisable to use tools that enhance the competitiveness of territories, develop intellectual capital and also increase welfare of population generally (GRP growth), as well as facilitate clustering. In conclusion, an effective implementation of the strategy of regional and municipal innovation systems need the following complexes of: information provision; expertise; financial and economic support, production support; certification; promotion R\&D and high-tech products; personnel training and retraining; coordination and regulation.

\section{ACKNOWLEDGEMENTS}

The article was published with the financial support from Ministry of Education and Science of the Russian Federation within the framework of state assignment to the project \#26.1511.2014K "Theory and methodology of managing innovational and investment processes in small business enterprises."

\section{REFERENCES}

1) Chitaya, G.O. (2006) Innovative determinant of industrial development of Russian macroregions. Federative Relations and Regional Socio-economic Policy, 3, 51-64.

2) Doroshenko, Y.A. and Kochetkova, O.V. (2006) Forms of innovative development of enterprises. Collection of Scientific Papers "Actual problems of economic development", BSTU named after V.G. Shukhov, Vol. 10, 25-27.

3) Kanishchev, R.Y. and Usmanov, D.I. (2013) Theory of roles and institutional factors affecting the innovative development of regional markets at the level of municipalities. Scientific and Technical Journal "Bulletin of BSTU named after V.G. Shukhov", 2, 115-121.

4) Karlinskaya, E.V. Innovation strategy of Russia: genesis and futurology, the practical realization under crisis conditions. Available at: http://www.rpm-consult.ru/pdf/article32.pdf.

5) Kirillina, M.V. and Myasoedov, I.A. (2010) The issue of a national innovation system. Economic Journal, 3, 127-133.

6) Kovalev, A.S. and Doroshenko, Y.A. (2013) Development of methodological approaches to the assessment of integration level of innovative forms of organization of the agro-industrial complex of the Russian Federation. Scientific and Technical Journal "Bulletin of BSTU named after V.G. Shukhov", 3, 133-135.

7) Lobanova, V.A. and Ismagilova, D.D. (2011) Comparative evaluation of the effectiveness of cluster integration. Scientific and Technical Journal "Bulletin of BSTU named after V.G. Shukhov", 1, 148-152.

8) Lundvall, B. (2011) He Invented a National Innovation Economy. Bulletin "Innovative Trends", 1, 3-4.

9) Malashevskaya, A.V. and Stryabkova, E.A. (2011) Theoretical framework of the concept of national innovation systems. Belgorod Economic Bulletin, 1-2 (61-62), 57-62.

10) Mukhamedyarov, A.M. (2008) Innovation Management (2nd Edition). Infra-M, Moscow.

11) Nikulina, T.Y. (2011) Assessment of the prospects of implementation of innovation cycle in a region. Proceedings of the 2 nd International Conference "Law, Economy and Management in Modern Ambience" (LEMiMA 2011), Belgrade, Serbia, April 12-15, Vol.3, 264-269. 
12) Pokhilko, T.N. (2010) Formation of an innovation system as a condition for social and economic development of a region. The Humanities and Social Sciences, 4, 23-33.

13) Spitsin, V.V. The organization and monitoring of the strategy of innovative development of a region (the Tomsk region). Available at: http:// www.lib.tsu.ru/mminfo/000063105/323/image/323-295.pdf

14) Stryabkova, E.A. and Kurbatov, V.L. (2012) Influence of cluster policy on the competitiveness of Russia and its regions. Scientific and Technical Journal "Bulletin of BSTU named after V.G. Shukhov", 2, 104-109.

15) Troshin, A.S. and Shevtsova, S.N. (2013) Determination of the background of special economic zone in the Belgorod region. Scientific and Technical Journal "Bulletin of BSTU named after V.G. Shukhov", 5, 146-149.

16) Vaganova, O.V. (2011) The mechanism of the intensification of innovative production.
Scientific and Technical Journal "Bulletin of BSTU named after V.G. Shukhov", 4, 92-95.

17) Vostretsov, A.I. (2013) The investigation of regional risk arising in the inter-regional transfer of elements of a regional reproductive potential (particularly innovative potential). Scientific and Technical Journal "Bulletin of BSTU named after V.G. Shukhov", 2, 130-133.

18) Yudin, A.V. and Gusev, S.A. (2006) Analysis of the national innovation system in Russia. Proceedings of the Regional Scientific and Practical Conference "Young scientists for the industry", Stary Oskol, Russia, Vol.1, 64-71.

19) Zarkovic, A.V. (2012) Theoretical framework of trans-territorial approach to understanding the concept of innovation systems. Collection of Papers of Young Scientists and Specialists of the Belgorod Region, Vol.1, 12-17.

Paper sent to revision: 24.10.2014.

Paper ready for publication: 12.12.2014. 